\title{
DESDE LOS UMBRALES DE LA INVENCIÓN: LA ENUNCIACIÓN METAFICCIONAL EN NABOKOV Y BORGES
}

\author{
Ana ABELLO VERANO \\ Universidad de León \\ aabev@unileon.es
}

A José Enrique, con el privilegio de haber sido su alumna

$\mathrm{V}$

inculado inexorablemente a la enunciación discursiva, la noción de metaficción surge hacia los años setenta del siglo XX y desde el mismo momento de su utilización es objeto de distintas discusiones teóricas y formulaciones bibliográficas. Como cualquier otro constituyente del instrumental terminológico literario ha sufrido modificaciones diacrónicas, bien referidas a su campo de aplicación o bien debidas a la multitud de taxonomías imperantes. Uno de los debates principales es la variación nominal que el fenómeno metaficcional sufre: fabulación, surfiction, antinovela, novela que se construye a sí misma, novela autorreferencial, transparente, autogenerada, ensimismada, reflexiva, autoconsciente, autorrepresentativa, narcisista, entre muchos otros términos que amplían la nómina. Las transformaciones léxicas también juegan con el prefijo griego 'meta' - metaliteratura, metanarración, metalenguaje, metatexto, metadiscurso, metadiégesis o metanovela - . De todo este conjunto, se consolida progresivamente el vocablo de metaficción para referirse al mismo aspecto narratológico ${ }^{1}$.

Todas las teorías sobre la metaficción que se han formulado se encuentran determinadas de forma notable por el contexto en que han surgido y por las corrientes intelectuales que las amparan ${ }^{2}$. Patricia Waugh resalta en uno de los estudios de referencia lo siguiente: «Metafiction is a term given to fictional writing which self-consciously and a systematically draws attention to its status as an artifact in order to pose questions about the relationship between fiction and reality» (1984: 2). La definición que proporciona es sumamente clarificadora y se asume como punto de partida para una profundización

\footnotetext{
${ }^{1}$ Más información sobre el discurso narrativo metaficcional y la problemática inherente a la cuestión taxonómica en Ródenas de Moya (1994-1995: 323-335).

${ }^{2}$ Zavala sintetiza con hondo criterio que «entre las primeras reflexiones teóricas sobre la metaficción podrían mencionarse la aproximación formalista de Lucien Dällenbach, la estructuralista de Gérard Genette, la pragmática de Linda Hutcheon, la constructivista de Patricia Waugh y la dialógica de Robert Stam» (2010: 362).
} 
Desde los umbrales de la invención: la enunciación metaficcional en Nabokov y Borges

mayor. El membrete de metaficción se suele emplear, por lo tanto, para aludir a los fenómenos autorreferenciales presentes en las obras literarias, si bien es cierto que en sus orígenes se circunscribe exclusivamente al dominio de un género concreto: la novela. Con el tiempo, en cambio, se ha considerado que esta acotación es demasiado rígida y se extiende su aplicación a otras formas expresivas, tanto literarias - metapoesía y metateatro - como no literarias — cine, publicidad, música - La metaficción constituye un estilo de escritura que incide de forma sistemática en la naturaleza ficcional del texto y está muy ligado a la reflexión discursiva. En este sentido, se configura de acuerdo a elementos de distinta índole centrados en la figura del narrador, en el mundo de los personajes y en el proceso de creación literaria, sin olvidar la continua interacción entre la realidad y lo irreal.

La crítica angloamericana es la que más empeño ha dedicado al estudio de este recurso literario, ocupándose de él con el fin de arrojar más luz al respecto. Uno de los primeros estudiosos que aborda, aunque sea de manera secundaria, las manifestaciones de la metaficción es John Barth, considerándolas una consecuencia directa del agotamiento de las técnicas narrativas más tradicionales. Incide en otros motivos característicos de la literatura del momento, como el elemento onírico y su contaminación con la vigilia o la imagen del laberinto como reflejo de las infinitas posibilidades de elección. Sin embargo, también alude a la metaficción, término que vincula a su conocido precepto de «literatura de la posibilidad agotada». Este teórico ofrece una panorámica de la literatura contemporánea, analizando en profundidad la obra del argentino Jorge Luis Borges y relacionándolo con otros escritores del momento como Samuel Beckett o Vladimir Nabokov. Todos ellos, máximos representantes de esa literatura del agotamiento, manejan con precisión las formas narrativas más anticuadas y las combinan con las más modernas, un hecho que convierte «la ultimidad sentida de su tiempo en materia y medio de su obra» (Barth, 1976: 177). El presente ensayo se centrará precisamente en las notables conexiones que se aprecian entre la producción prosística de Nobokov y Borges, abordando a grandes rasgos la metaficción en las Américas ${ }^{3}$. Con ese propósito contrastivo, abordaré la novela Pálido Fuego, del primero, y uno de los relatos que considero más significantes de la ingente obra del autor nacido en Buenos Aires.

La narrativa de Nabokov, no solo la breve sino también la extensa, se encuentra impregnada de numerosos elementos de carácter metaficcional ${ }^{4}$. Esta tendencia se convierte en un aspecto definitorio de su obra y pone de relieve la propia construcción de las composiciones y su evidente condición de artefacto estético. La ficción se convierte en el espacio expresivo idóneo para incorporar comentarios sobre su naturaleza lingüística, generando piezas literarias dentro de otras. A pesar de que Pálido Fuego se publica en el año 1962, mucho antes de que se empiece a hablar del postmodernismo en las

\footnotetext{
${ }^{3}$ La relación entre ambos escritores ha sido contemplada en numerosas ocasiones. Se puede consultar un amplio listado de este tipo de trabajos en la tesis doctoral de Kressova (2007: 11-19).

${ }^{4}$ Han sido muchos los críticos que consideran a Nabokov un escritor metaficcional, definiendo la obra metaficcional en los siguientes términos: «A fully self-conscious novel, however, is one in which from beginning to end, through the styles, the handling of narrative viewpoint, the names and words imposed on the characters, the patterning of the narration, the nature of the characters and what befalls them, there is a consistent effort to convey to us a sense of the fictional world as an authorial construction set up against a background of literary tradition and convention» (Barreras Gómez, 2005: 106).
} 
esferas críticas, su carácter experimental y la originalidad inventiva de la obra permiten incluirla en este estudio como ejemplo paradigmático de dicho movimiento y de la metaficción. John Barth define la obra como «una buena novela escrita por un pedante culto, en forma de un comentario pedante sobre un poema inventado para ese propósito» (1976: 177-178).

Pálido fuego supone un artificio literario vuelto sobre sí mismo, con el efecto de manifestar un mundo literario autónomo partiendo del palimpsesto o manuscrito. El manuscrito, que no es encontrado sino voluntariamente entregado, constituye en este caso una ficción hipertextual, un poema escrito por el escritor norteamericano John Shade, tiempo antes de ser asesinado. De este modo, el libro aparece como una edición póstuma. De acuerdo a una estructura tripartita, la obra consta de un breve prólogo, un extenso poema y una última parte en la que se recogen profusas notas y aclaraciones acerca del texto poético. Se rompe totalmente la linealidad discursiva a favor de una lectura fragmentada que obliga al lector - inhabituado a este tipo de disposición — a consultar los comentarios y volver una y otra vez sobre el poema. Así se revalúa y reconstruye lo narrado. La parte nuclear es la composición lírica, que funciona como creación independiente, pero tanto el prólogo que le precede como las anotaciones críticas posteriores facilitan el proceso de comprensión de la misma. El prólogo, que aparece firmado por Charles Kintobe, se configura como una auténtica guía de lectura que ha de leer de manera inexcusable todo aquel que quiera aproximarse a esta publicación:

De ese poema debemos ocuparnos ahora. Mi prólogo no ha sido, así lo espero, demasiado magro. Otras notas, ordenadas en un comentario sostenido, satisfarán seguramente al lector más voraz. Aunque esas notas, con arreglo a la costumbre, vienen después del poema, se aconseja al lector consultarlas primero y luego estudiar el poema con su ayuda, releerlas naturalmente al seguir el texto y quizá, después de haber terminado el poema, consultarlas por tercera vez para completar el cuadro (Nabokov, 2009: 7).

Los consejos proporcionados ratifican, tal y como ya ha constatado Barreras Gómez, que el receptor idóneo para el autor de origen ruso es aquel «que relee varias veces su obra, recuerda datos, los contrasta, se da cuenta de las alusiones, entiende sus juegos de palabras y sus ironías y, en general, comprende la totalidad del texto» (2005: 117). Las disertaciones no se limitan exclusivamente al ámbito ficcional, sino que dan un paso más allá y aparecen referidas al plano extratextual en el que parece encontrarse ese narrador-editor-comentador. Está claro que la descodificación de la obra demanda un tipo de receptor capaz de desplegar estrategias similares —en cuanto a su complejidada las que han sustentado la creación de la misma. Además, al final del prólogo Charles Kinbote pone en entredicho la autoridad del autor, con una actitud pretenciosa:

Permítaseme afirmar que sin mis notas, el texto de Shade simplemente no tiene realidad humana alguna, pues la realidad humana de un poema como el suyo (demasiado caprichosa y reticente para una obra autobiográfica), con la omisión de muchos versos medulosos rechazados por él, tiene que depender totalmente de la realidad de su autor y lo que le rodea, de sus afectos y así sucesivamente, realidad que solo mis notas pueden proporcionar. Probablemente mi querido poeta no hubiera suscrito esta afirmación pero, para bien o para mal es el comentador el que tiene la última palabra (Nabokov, 2009: 7).

El narrador, por lo que puede deducirse, se considera también compositor e inventor del relato porque sin su intervención en el proceso de edición, el resultado final no habría sido el mismo. Sin 
embargo, el comentario que aporta y que resulta esclarecedor para comprender el poema es en sí una auténtica digresión. Las consideraciones que remiten a líneas específicas y numeradas del poema se refieren a los mecanismos de construcción del mismo, pero amplían la información a partir de la relación que en la realidad mantenían el poeta y el editor. La voz narradora evoca el pasado de Shade recurriendo a los recuerdos que aún prevalecen en su memoria, pero al mismo tiempo concediéndoles un cariz imaginativo. Al recrear lo pretérito en el presente del discurso literario, se confrontan también las dimensiones de realidad y ficción, tan frecuentes al hablar de metaficción, porque en ningún momento puede saberse con seguridad el grado de veracidad de lo narrado. Esto supone transgredir totalmente las fronteras entre ficción literaria y aspectos extraliterarios, haciendo que la duda impregne toda la lectura.

Por otro lado, el poema adquiere el tono de una autobiografía pero no por ello ha de sostenerse un pacto de verdad entre lo narrado y el autor, del mismo modo que no puede considerarse verdadera la vinculación entre Charles Kinbote y John Shade. La metaficción en este caso se erige como una forma de indagar en los intersticios de los mecanismos narrativos y en las sombras de lo racional. El lector nabokoviano debe aprender a no fiarse completamente del narrador; quizás este no quiera informarle con precisión de todos los aspectos, de ahí que la línea divisoria entre realidad y fícción se torne siempre quebradiza, porosa. No es azaroso tampoco que tanto la voz narrativa como el supuesto creador del poema dediquen su trayectoria académica al estudio de la literatura. Se alude a que ambos se conocen en la Universidad, y esta pasión desmedida por el poder sugestivo de las palabras supone otro guiño ficcional a mayores en el conjunto de la novela. De este modo, se refleja el ambiente literario que envuelve a los dos personajes y que tendrá también repercusión en la composición del poema. El mundo exterior como contexto de creación o sustrato realista se asimila a la esfera literaria.

La trama, en definitiva, se limita a reproducir la historia que rodea a toda la elaboración de la propia trama narrativa. No faltan en ella menciones a otras obras maestras de la tradición literaria estableciendo una red intertextual que no deja de ser un juego de alusiones explícitas- y un tono detectivesco. Gracias a las detalladas anotaciones de Charles Kinbote, el lector va teniendo acceso progresivamente a una identidad que no parece responder en absoluto a un hombre equilibrado. Pese a lo que pueda pensarse, la labor crítica que ofrece el narrador constituye una historia paralela por todo lo que deja entrever de la personalidad engañosa del personaje.

Por lo que se refiere a la figura de Jorge Luis Borges, es posible afirmar que son pocos los escritores que, como él, han sabido sintetizar y sublimar de una forma tan intensa la filosofía en la literatura. Fruto de su profunda erudición y de la potencia estética de su prosa, la mayoría de sus cuentos parten de una inquietud metafísica. A través de sus textos, Borges manifiesta sus preocupaciones filosóficas en torno al destino del hombre, el carácter cíclico del tiempo, la naturaleza del espacio, la probabilidad, la memoria, la eternidad, el infinito, los actos secretamente conectados, la predestinación, el sueño, la unidad y la multiplicidad, la inconsistencia del mundo o la muerte; interrogantes todos ellos que responden a la necesidad imperiosa de descubrir los enigmas que rodean la vida humana. La producción cuentística del argentino está marcada por el escepticismo 
epistemológico y es precisamente este trasfondo el que le lleva a falsear los datos vertidos en el texto y a aumentar el nivel de metalenguaje como herramienta para enriquecer la ficción. La metaficción relacionada con su idea de lo infinito — se convierte así en una de las estrategias más recurrentes de su obra, sin olvidar sus ingeniosos juegos mentales y sus paradojas.

Relatos como «El inmortal», «El Aleph», «Tlön, Uqbar, Orbis Tertius»o «Pierre Menard, autor del Quijote» constituyen ejemplos significativos del recurso de la metaficción. Cada una de estas composiciones merecería un estudio detallado, pero con el fin de ofrecer una exposición panorámica del tratamiento de la metaficción, reduciré el comentario al último relato, una composición que no ha dejado nunca de interesar a la crítica y de suscitar, por ello, nuevos análisis. «Pierre Menard, autor del Quijote» se publica en la revista Sur hacia el año 1939 y aparece cinco años más tarde como parte integrante de la antología Ficciones. Su elección responde a que el propio Borges lo considera la composición inicial de ese universo de tintes fantásticos y perturbadores que empieza a crear y que al mismo tiempo supone una ruptura fundamental con la dedicación ensayística y poética de su trayectoria literaria anterior. Silvia Mohillo recoge las propias palabras del argentino en uno de los diversos ensayos que le ha dedicado: «Entonces decidí escribir algo, pero algo nuevo y diferente para mí, para poder echarle la culpa a la novedad del empeño si fracasaba» (1979: 53). Se produce pues el paso definitivo hacia la escritura imaginativa.

Fruto de un evidente proceso de renovación estética, en este cuento dedicado a Silvina Ocampo, la metaficción está más presente que en otras de sus composiciones, si bien aparece íntimamente relacionada con el concepto de la reescritura. La obra protagonista que da sentido a la composición es ya de por sí un ejemplo ilustrativo de escritura metaficcional en la historia de la literatura española. No se puede olvidar a este respecto que la novela de Cervantes, considerada parte del canon literario universal, subvierte los códigos tradicionales del género e incorpora breves historias intercaladas de matemática diversa - pastoril, sentimental, morisca, picaresca o ejemplar- Con esto pretende conseguir variedad dentro de la unidad, de acuerdo con la estética barroca.

Borges, como en tantas ocasiones, hace gala de su deslumbrante ingenio al convertir el texto literario en un producto híbrido, en una mezcla entre ensayo de carácter erudito y ficción en el sentido estricto del término. Se trata de una pieza cuentística que participa de la ruptura premeditada de categorías genéricas y, en consecuencia, de la fusión de distintos elementos procedentes de la crítica literaria, la indagación filosófica o la reseña. No se produce una homonimia entre Borges y el narrador, presente en otros cuentos como «El otro» o «Agosto 25, 1983», sino que el narrador innominado encuentra un vínculo de unión con el personaje principal, escritor imaginario, y a partir de ahí se inicia la narración. El Borges real da forma narrativa a un crítico innominado del escritor imaginado Pierre Menard.

El narrador proporciona una minuciosa descripción de lo que denomina la «obra visible» (2017: 30) del vanguardista francés Menard, llegando incluso a enumerarla en orden cronológico como si de un conjunto de referencias bibliográficas se tratase. Así, alude a composiciones poéticas en forma de sonetos, monografías, artículos técnicos, traducciones, notas críticas, prólogos, ediciones, exámenes 
Desde los umbrales de la invención: la enunciación metaficcional en Nabokov y Borges

de leyes métricas, definiciones, réplicas y listas manuscritas. Esta información acerca de la producción de Menard aparece a modo de inventario avalado y no se circunscribe únicamente a lo publicado, sino que engloba también la obra no conocida. Esa otra producción — «la subterránea, la interminablemente heroica, la impar» (2017: 32)— está constituida por un único libro que es ni más ni menos que $E l$ Quijote, un dato que cuestiona la figura autorial de Miguel de Cervantes. El intelectual está intentando producir — no ya copiar o transcribir - la obra maestra del imaginario literario occidental y generar así una red de significados imposibles de encontrar en el original:

\footnotetext{
No quería componer otro Quijote - lo cual es fácil— sino el Quijote. Inútil agregar que no encaró nunca una trascripción mecánica del original; no se proponía copiarlo. Su admirable ambición era producir unas páginas que coincidieran - palabra por palabra y línea por línea- con las de Miguel de Cervantes (Borges, 2017: 33).
}

Crea pues «un Quijote del siglo XX idéntico al de Cervantes y a su vez inmensamente más rico» (Alazraki, 1974: 141). Esto se debe a las interpretaciones extraídas de la lectura concienciada del libro; él es el reflejo del lector ideal que conoce a la perfección el texto y las circunstancias que rodean toda su producción. Como resultado de esa aguda lectura se convierte en el creador del mismo libro, una obra preexistente, para otorgarle significaciones únicas, algo que resulta extremadamente insólito: «Menard (acaso sin quererlo) ha enriquecido mediante una técnica nueva el arte detenido y rudimentario de la lectura: la técnica de anacronismo deliberado y de las atribuciones erróneas» (2017: 37). Además, el reflejo del proceso de escritura también queda patente porque el narrador hace alusión a la multiplicidad de borradores y a la corrección tenaz y continuada de los mismos. Una vez más, la memoria ocupa un lugar preeminente al poner de relieve los entresijos creativos, dado que el narrador afirma recordar «sus cuadernos cuadriculados, sus negras tachaduras, sus peculiares símbolos tipográficos y su letra de insecto» (2017: 37), información que curiosamente se ubica en una nota al pie de página.

Por otro lado, el uso de la intertextualidad no solo comprende la cita a obras capitales como la Odisea y la Eneida, los capítulos del texto de Cervantes o la mención al resto de su producción en prosa como la Galatea, las Novelas Ejemplares, Los trabajos de Persiles y Segismunda y el Viaje del Parnaso. La intertextualidad se hace más patente al incluir en el propio relato referencias directas a escritores consagrados - Novalis, William Shakespeare, Edgar Allan Poe, Charles Baudelaire, Stéphane Mallarmé, Paul Valéry, James Joyce, Louis Ferdinand Céline, Francisco de Quevedo- y a grandes representantes del ideario filosófico.

Es necesario mencionar que la técnica del mise en abyme, tan típica del postmodernismo, también genera perplejidades en torno al estatuto de ficción de una literatura que puede basarse en sí misma. Al comienzo del relato se menciona que Pierre Menard solo tiene escritos dos capítulos de El Quijote y un breve fragmento de un tercer capítulo. El primero de ellos coincide con el Capítulo IX del texto original, donde se narra el descubrimiento del manuscrito inédito de Cide Hamete Benengeli y su consiguiente traducción. En este sentido, puede apreciarse una sucesión de secuencias narrativas de tipo inclusivo: Pierre Menard compone El Quijote de Cervantes del mismo modo que Cervantes 
compuso la obra de Benengeli. El proceso de reproducción literaria no acaba ahí, pues el narrador del relato, como último responsable del texto, asume «el misterioso deber de reconstruir literalmente su obra espontánea» (2017: 35). No se agotan las posibilidades interpretativas con este análisis, que resulta a todos los efectos sucinto en comparación con la riqueza del universo borgiano y con su interés epistemológico de explorar las fisuras del paradigma de la realidad. No obstante y con el fin de ofrecer una síntesis sobre este relato tan peculiar, quizás la mejor opción sea hacerse eco de las siguientes palabras:

\footnotetext{
Pero lo que es importante observar es que Borges no se atribuye el Quijote a sí mismo, y mucho menos lo recompone como Pierre Menard; en su lugar, escribe una obra de literatura original y notable, cuya tema implícito es la dificultad, tal vez la falta de necesidad, de escribir obras originales de literatura. Su victoria artística, si se quiere, reside en que confronta un callejón sin salida y lo emplea contra sí mismo para conseguir una obra nueva (Barth, 1976: 175).
}

Con la premisa de que «cada texto metaficcional construye su propio contexto de interpretación» (Zavala, 2010: 355), puede afirmarse que las composiciones de índole metaficcional postulan los límites y las posibilidades del lenguaje, así como el significado del proceso de escribir y el consiguiente acto de lectura. La metaficción en Nabokov es una técnica narrativa de carácter lúdico y de efectos transgresores, que no está exenta de matices humorísticos. En consonancia con los preceptos más reconocibles y definitorios del postmodernismo, el autor juega de una forma totalmente deliberada con el lector al convertir la mayor parte de Pálido Fuego en notas o comentarios críticos a un poemamarco, revelando explícitamente la elaboración ficcional. El uso de la metaficción provoca un efecto de divertimento en el lector y refleja el acto de escritura «como un juego intelectual creado para sus lectores. Para participar en este juego, el lector debe hacer los movimientos pertinentes y entender cada alusión. Su lector es un relector que analiza los textos para comprender todos sus aspectos» (Barreras Gómez, 2005: 152).

El enfoque de Nabokov contrasta con la metaficción en términos metafísicos de Borges, de calado más hondo. En los relatos del argentino, este recurso literario adquiere una dimensión profunda y está relacionado con la idea de infinito. El lector también se convierte en un jugador dispuesto a resolver el puzle o la encrucijada que le presenta cada relato para poder deducir al menos una parte de lo que está ocurriendo. Además, al lector borgiano se le presupone un determinado bagaje cultural, una formación general que le permita interpretar los distintos niveles ficcionales que se presentan y que no son en ningún caso fáciles de apreciar. Las intenciones del argentino, por lo tanto, no se sabe muy bien dónde empiezan ni dónde acaban porque no quedan reducidas al mero engranaje narrativo, sino que lo superan y trascienden, generando múltiples dudas.

Pese a las diferencias ya apuntadas entre ambos escritores y reducidas al distinto modo de emplear y dar sentido a la metaficción, hay que incidir de nuevo en el elemento de unión entre los dos: el papel que desempeña el lector. Tanto las composiciones de Nabokov como de Borges precisan de un lector activo que quiera distinguir los distintos niveles de lectura propuestos por los autores en los 
Desde los umbrales de la invención: la enunciación metaficcional en Nabokov y Borges

textos ${ }^{5}$. Los lectores de ambos deben estar abiertos a nuevas posibilidades y experiencias; solo de esta manera dejarán de ser receptores pasivos y se convertirán en verdaderos partícipes del significado de la obra, lo que supondría otorgarle una concepción circular al artefacto literario.

\section{Bibliografía}

AlAZRAKI, J. (1974): La prosa narrativa de Jorge Luis Borges. Madrid, Gredos.

BARRERAS Gómez, A. (2005): El estudio de los relatos de Vladimir Nabokov. Su narrador, su lector y sus personajes. La Rioja, Servicio de Publicaciones de la Universidad de la Rioja.

BARTH, J. (1967): «Literatura del agotamiento» en J. AlAZRAKI, ed., Jorge Luis Borges. Madrid, Taurus, Serie El escritor y la crítica, pp. 170-182, 1976.

Borges, J. L. (1939): «Pierre Menard, autor del Quijote», en Borges esencial. Edición conmemorativa de la RAE y la ASALE, pp. 30-38, 2017.

CORTÁZAR, Julio (1974): Rayuela. Cátedra, Madrid, 2008.

MohILlo, S. (1979): Las letras de Borges. Buenos Aires, Editorial Sudamericana.

NaboKov, V. (1962): Pálido Fuego, Madrid, Anagrama, 2009.

RóDEnas De Moya, D (1994-1995): «Metaficción y metaficciones: Del concepto y las tipologías», Tropelías: Revista de teoría de la literatura y literatura comparada, nº 5-6, pp. 323-335.

Kressova, N. (2007): Bajo el signo de Proteo. Estudio comparado de temas y motivos en las obras de J.L. Borges y V. Nabokov. Granada, Universidad de Granada.

Waugh, P. (1984): Metafiction: The Theory and Practice of Self-Conscious Fiction. Londres, Routledge.

ZAVALA, L. (2010): «Leer metaficción es una actividad riesgosa», Literatura: teoría, historia y crítica, $\mathrm{n}^{\mathrm{o}} 12$, pp. 353-369.

\footnotetext{
${ }^{5}$ El concepto de lector activo queda explicitado en un fragmento de Rayuela, donde Cortázar contrapone esta figura a la del «lector-hembra», término equivalente al lector pasivo que busca una lectura totalmente dirigida y sin implicaciones emocionales: «Morelli entiende que el mero escribir estético es un escamoteo y una mentira, que acaba por suscitar al lector-hembra, al tipo que no quiere problemas sino soluciones, o falsos problemas ajenos que le permiten sufrir cómodamente sentado en su sillón sin comprometerse en el drama que debería ser el suyo» (2008: 611).
} 